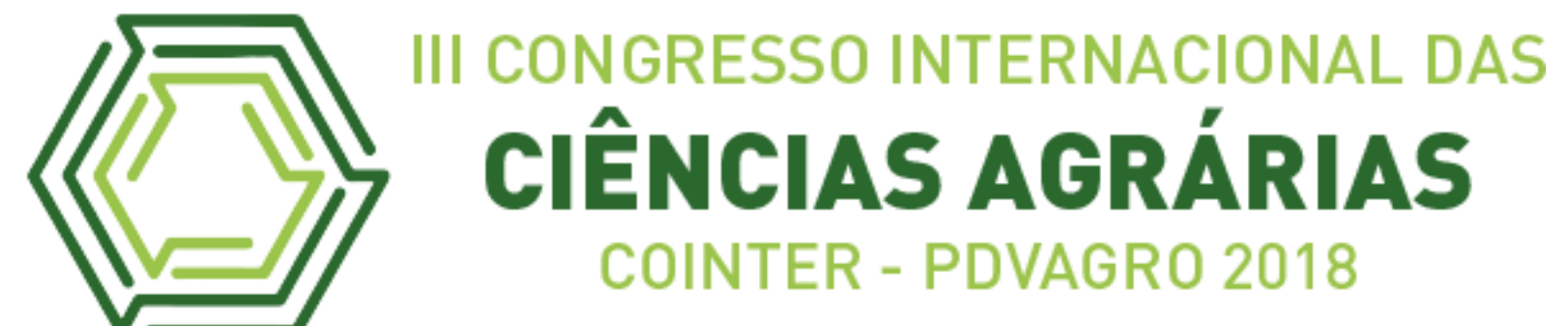

\title{
DESEMPENHO PRODUTIVO DE POEDEIRAS ALIMENTADAS COM DIFERENTES FONTES DE CÁLCIO
}

\section{PRODUCTIVE PERFORMANCE OF POEDEIRAS FURNISHED WITH DIFFERENT SOURCES OF CALCIUM}

\author{
Apresentação: Pôster \\ Nicolas Lima Silva ${ }^{1}$; Hiagos Felipe Firmino de Lima ${ }^{2}$; Otoniel Felix de Souza ${ }^{3}$; \\ Marcelle Santana de Araújo ${ }^{4}$
}

\section{DOI: https://doi.org/10.31692/2526-7701.IIICOINTERPDVAGRO.2018.00418}

\section{Introdução}

A avicultura tem se destacado no mercado mundial, grande parte desse crescimento deve-se a produção de ovos. Tal sucesso é possível pelas inúmeras contribuições de pesquisas cientificas aliadas ao incentivo financeiro no ramo, que torna o setor mais rentável e atrativo para produtores. Com esses avanços foi possível produzir, somente no Brasil, cerca de 39,1 bilhões de ovos no ano de 2016 (ABPA, 2017).

Buscando sempre o aumento da quantidade e da qualidade na produção avícola, várias organizações realizam pesquisas visando, principalmente, o aumento produtivo ou redução do custo de produção. Fatores estes que podem ser influenciados pela utilização de diferentes componentes na alimentação, tendo em vista que a alimentação é responsável por cerca de $60 \%$ dos custos na produção de ovos (GIROTTO, 2008). Entretanto, a modificação nos constituintes da ração para melhor adequação da mesma à realidade do produtor, não pode influenciar negativamente na qualidade do produto final.

\section{Fundamentação Teórica}

\footnotetext{
${ }^{1}$ Graduando em Zootecnia na Universidade Federal Rural do Semiárido, UFERSA, niclimasilva@ hotmail.com

2 Zootecnista, Mestre em Zootecnia pela Universidade Federal Rural do Semiárido, UFERSA, hiagosflima@gmail.com

3 Pós-graduando na Universidade Federal do Ceará, UFERSA, otonielflx@hotmail.com

${ }^{4}$ Docente na Universidade Federal Rural do Semiárido, UFERSA, marcelle@ufersa.edu.brx
} 
No que se diz respeito à produção de ovos, o cálcio se destaca na composição de rações balanceadas, sendo determinante na composição de casca e demais componentes do ovo. Além disso, o suprimento desse mineral para matrizes produtoras pode evitar inúmeras complicações ocorridas em casos de deficiências.

Inúmeros compostos são tidos como potencias fontes de cálcio, sejam eles orgânicos (farinha de ossos, conchas, e algas) ou inorgânicos (rochas) (MELO \& MOURA, 2009). No entanto, sem análise prévia para utilização na nutrição de aves poedeiras encontram-se incertezas quanto a sua eficácia para este fim.

Com isso, objetivou-se avaliar o desempenho de galinhas poedeiras alimentadas com rações contendo diferentes fontes de cálcio em substituição à fonte convencional, o calcário calcítico.

\section{Metodologia}

O experimento foi desenvolvido no Setor de Avicultura da Universidade Federal Rural do Semi-Árido, localizada em Mossoró/RN. Foram utilizadas 120 frangas da linhagem Bankiva, uniformizadas quanto à produção de ovos e ao peso corporal. O período experimental foi contabilizado a partir desta data e teve duração de 84 dias. As análises de qualidade de ovos, foram feitas 2 vezes por semana, totalizando-se 12 análises, durante todo período experimental.

A distribuição dos animais foi feita em delineamento inteiramente ao acaso, com quatro tratamentos, onde cada tratamento foi composta por 10 repetições com 3 aves por unidade experimental. Os tratamentos foram constituídos por quatro rações experimentais, contendo diferentes fontes de cálcio: 1) calcário calcítico; 2) farinha de concha de búzio (Anomalocardia brasiliana); 3) farinha de concha de ostra e 4) farinha de casca de ovo.

As rações foram formuladas a base de milho e farelo de soja, suplementadas com minerais e vitaminas, de forma a atender as exigências nutricionais propostas por Rostagno et al. (2011) para galinhas poedeiras semipesadas.

As características de desempenho avaliadas foram número de ovos por unidade experimental, taxa de postura (\%), peso médio dos ovos (g), massa de ovos (ave/g/dia), consumo de ração (ave/g/dia), conversão alimentar por massa de ovo (g ração/massa ovo), qualidade externa dos ovos.

A análise das hipóteses experimentais foi subsidiada através da análise estatística dos dados, mediante análise de variância e teste de médias comparadas pelo teste Tukey a 5\% de 
probabilidade, utilizando-se programa computacional R 2011.

\section{Resultados e Discussões}

Em relação ao consumo de ração e conversão alimentar por massa de ovos não se obteve diferença significativa nas diferentes fontes de cálcio $(P>0,05)$, tal resultado foi encontrado por Reis et al. (2002) que testando fontes de origem orgânica não encontraram diferença no desempenho de codornas japonesas. Bem como para taxa de postura nos tratamentos contendo calcário calcítico, farinha de concha de búzio e farinha de concha de ostra, não diferindo entre si. Todavia, o tratamento contendo a farinha da casca de ovo apresentou menor desempenho (Tabela 1), fato esse que pode ser explicado devido a menor granulometria desta farinha quando comparada as demais. Bueno (2003) relata que partículas finas de cálcio são rapidamente solubilizadas e, por isso, perde a capacidade de fornecer cálcio continuamente.

Tabela 1 - Taxa de postura, consumo de ração e conversão alimentar de poedeiras alimentadas com dietas contendo diferentes fontes de cálcio. Fonte: Própria

\begin{tabular}{|c|c|c|c|c|c|c|}
\hline & \multicolumn{4}{|c|}{ Fontes de Cálcio } & \multirow[b]{2}{*}{ Média } & \multirow[b]{2}{*}{$\mathrm{CV}(\%)$} \\
\hline & $\begin{array}{l}\text { Calcário } \\
\text { Calcítico }\end{array}$ & $\begin{array}{l}\text { Farinha de } \\
\text { concha de } \\
\text { Búzio }\end{array}$ & $\begin{array}{c}\text { Farina de } \\
\text { concha de } \\
\text { Ostra }\end{array}$ & $\begin{array}{c}\text { Farinha de } \\
\text { Casca de } \\
\text { Ovo }\end{array}$ & & \\
\hline $\begin{array}{c}\text { Taxa de postura } \\
(\%)\end{array}$ & $77,04^{\mathrm{a}}$ & $75,85^{\mathrm{a}}$ & $80,87^{\mathrm{a}}$ & $65,07^{\mathrm{b}}$ & 74,71 & 10,01 \\
\hline $\begin{array}{c}\text { Consumo de } \\
\text { Ração (g) }\end{array}$ & 93,78 & 96,47 & 96,04 & 90,24 & 94,13 & 6,90 \\
\hline $\begin{array}{c}\text { Conversão } \\
\text { alimentar/Massa } \\
\text { de ovos }\end{array}$ & 2,23 & 2,29 & 2,28 & 2,30 & 2,27 & 14,32 \\
\hline
\end{tabular}

Da mesma forma, para os parâmetros relacionados à qualidade externa dos ovos (Tabela 2), as rações contendo calcário calcítico, farinha de concha de búzio e farinha de concha de ostra, não proporcionaram diferenças, por outro lado, aves alimentadas com farinha de casca de ovo realizaram postura de ovos com menor espessura da casca, fato este que pode estar associado à menor granulometria da fonte em relação às demais. Todavia utilizando uma granulometria mais grossa permitiu uma melhor concentração aumentando o percentual de casca, esses dados são reafirmados por Jardim Filho et al. (2005), que utilizando uma granulometria grossa, obtiveram melhor desempenho.

O peso relativo da gema, nos diferentes tratamentos, não foi afetado, porém o peso 
relativo de albúmen apresentou menor média para o tratamento com farinha de casca de ovo. Porém, Ito et al. (2006) no seu trabalho não constataram efeito dos níveis de cálcio e da granulometria para o peso relativo de gema e de albúmen. Para as variáveis, peso e altura da gema e peso do albúmen, observou-se melhor resultado para ração com calcário calcítico, farinha de concha de búzio e farinha de concha de ostra, contudo, não houve diferença significativa para altura do albúmen. Tais resultados podem ser explicados devido à granulometria destas farinhas e da sua maior biodisponibilidade de cálcio.

Com relação à Unidade Haugh e índice de gema e de albúmen, os valores analisados foram não significativos quando comparados os diferentes tratamentos. Guo \& Kim (2012), em sua pesquisa não encontraram efeitos da fonte de cálcio nesta variável. Resultados, neste trabalho, encontram-se dentro dos padrões de qualidade que devem ser superiores a 72 (USDA, 2000). Finalmente, foi verificado efeito dos tratamentos sobre a coloração da gema, tendo melhor resultado para ração que continha calcário calcítico.

Tabela 2 - Parâmetros relacionados à qualidade externa dos ovos. Fonte: Própria

\begin{tabular}{|c|c|c|c|c|c|c|}
\hline & \multicolumn{4}{|c|}{ Fontes de Cálcio } & \multirow[b]{2}{*}{ Média } & \multirow[b]{2}{*}{$\mathrm{CV}(\%)$} \\
\hline & $\begin{array}{l}\text { Calcário } \\
\text { Calcítico }\end{array}$ & $\begin{array}{c}\text { Farinha de } \\
\text { concha de } \\
\text { Búzio }\end{array}$ & $\begin{array}{c}\text { Farina de } \\
\text { concha } \\
\text { de Ostra }\end{array}$ & $\begin{array}{c}\text { Farinha } \\
\text { de Casca } \\
\text { de Ovo }\end{array}$ & & \\
\hline Ovo (g) & $57,03^{\mathrm{a}}$ & $58,44^{\mathrm{a}}$ & $57,89^{\mathrm{a}}$ & $53,84^{\mathrm{b}}$ & 56,8 & 4,87 \\
\hline $\begin{array}{l}\text { Altura do } \\
\text { albúmen }\end{array}$ & 8,28 & 8,79 & 8,34 & 8,49 & 8,48 & 6,14 \\
\hline $\begin{array}{c}\text { Altura da } \\
\text { gema }\end{array}$ & $17,71^{\mathrm{a}}$ & $17,88^{\mathrm{a}}$ & $17,63^{\mathrm{a}}$ & $17,06^{\mathrm{b}}$ & 17,57 & 3,79 \\
\hline $\begin{array}{c}\text { Coloração } \\
\text { de Gema }\end{array}$ & $3,41^{\mathrm{a}}$ & $2,99^{\mathrm{b}}$ & $2,88^{\mathrm{b}}$ & $2,93^{\mathrm{b}}$ & 3,03 & 7,32 \\
\hline Gema $(\%)$ & 22,26 & 21,82 & 22,04 & 21,46 & 21,89 & 5,26 \\
\hline Casca $(\%)$ & $9,56^{\mathrm{ab}}$ & $9,78^{\mathrm{a}}$ & $9,49^{\mathrm{ab}}$ & $9,09^{\mathrm{b}}$ & 9,48 & 4,73 \\
\hline $\begin{array}{c}\text { Albúmen } \\
(\%)\end{array}$ & $68,16^{\mathrm{a}}$ & $68,39^{\mathrm{a}}$ & $68,30^{\mathrm{a}}$ & $65,70^{\mathrm{b}}$ & 67,64 & 3,46 \\
\hline $\begin{array}{c}\text { Índice de } \\
\text { gema }\end{array}$ & 0,47 & 0,48 & 0,47 & 0,46 & 0,47 & 3,7 \\
\hline $\begin{array}{l}\text { Índice de } \\
\text { albúmen }\end{array}$ & 0,13 & 0,14 & 0,13 & 0,14 & 0,14 & 7,58 \\
\hline
\end{tabular}




\begin{tabular}{|c|c|c|c|c|c|c|}
\hline $\begin{array}{c}\text { Espessura } \\
\text { de casca } \\
(\mathrm{mm})\end{array}$ & $0,32^{\mathrm{a}}$ & $0,33^{\mathrm{a}}$ & $0,32^{\mathrm{a}}$ & $0,30^{\mathrm{b}}$ & 0,32 & 4,73 \\
\hline $\begin{array}{c}\text { Unidade } \\
\text { Haugh }\end{array}$ & 91,01 & 93,96 & 91,16 & 90,86 & 91,75 & 3,78 \\
\hline
\end{tabular}

\section{Conclusões}

As farinhas de concha de búzio e de concha de ostra podem ser usadas como alternativa à fonte de cálcio convencional em rações de poedeiras. No entanto, a farinha de casca de ovo proporcionou resultados insatisfatórios no desempenho e na maioria das variáveis de qualidade de ovo.

\section{Referências}

ABPA, Associação Brasileira de Proteína Animal. Relatório anual - 2017: Ovos. Disponível em:

<http://abpa.br.com.br/storage/files/3678c_final_abpa_relatorio_anual_2016_portugues_web_ reduzido.pdf $>$. Acesso em: 05 outubro. 2018.

BUENO, I. J. M. Influência da granulometria do calcário em ovos de matrizes avícolas de segundo ciclo. 2013. 42p. Dissertação (Mestrado) - Universidade Federal do Paraná, Curitiba.

GIROTTO, A. F. Custo de produção de ovos . Concórdia: Embrapa Suínos e Aves, 2008. 45p. (Embrapa Suínos e Ave. Documentos, 127).

ITO, D. T.; FARIA, D. E.; KUWANO, E. A.; JUNQUEIRA, O. M.; ARAUJO, L. F. Efeitos do fracionamento do calcio dietario e granulometria do calcário sobre o desempenho e qualidade dos ovos de poedeiras comerciais. Acta Scientiarum Animal Sciences, Maringa, v. 28 , n. 2, p. 187-195, 2006.

JARDIM FILHO, R.M.; STRINGHINI, J.H.; CAFÉ, M.B.; LEANDRO, N.S.M.; CUNHA, W.C.P.; NASCIMENTO Jr., O. Influência das fontes e granulometria do calcário calcítico sobre o desempenho e qualidade da casca dos ovos de poedeiras comerciais. Acta Sientiarum. Animal Sciences, v.27, n.1, p.35-41, 2005.

MELO, T. V.; MOURA, A. M. A. Utilização da farinha de algas calcáreas na alimentação animal. Archivos de zootecnia, Cordoba, v. 58, n. 1, p. 99-107, 2009.

REIS, S.R.; BARRETO, S.L.T.; LIMA, H.J.D.; PAULA, E.; MUNIZ, J.C.L.; MENCALHA, R.; VIANA, G.S.; BARBOSA, L.M.R. Substituição do calcário por farinha de casca de ovo na dieta de codornas japonesas no período de 40 a 52 semanas de idade. Revista Brasileira de Agropecuária Sustentável, Viçosa - MG, v.2, n.1, p. 107 - 112, Julho, 2012. 
ROStagnO, H.S. et al., Tabelas Brasileiras para Aves e Suínos: Composição de Alimentos e Exigências Nutricionais. $3^{a}$ ed., Viçosa: UFV, Imprensa Universitária, 35p, 2011. 